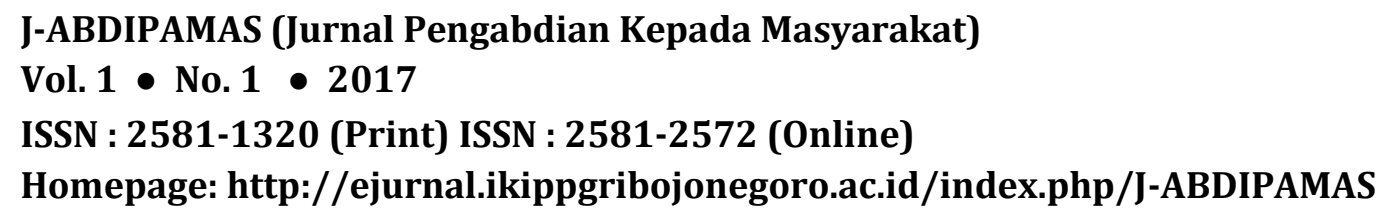

ISSN : 2581-1320 (Print) ISSN : 2581-2572 (Online)

Homepage: http://ejurnal.ikippgribojonegoro.ac.id/index.php/J-ABDIPAMAS

\title{
PELATIHAN PENGGUNAAN BAHASA INGGRIS UNTUK PARIWISATA (ENGLISH FOR TOURISM) BAGI SISWA SMKN 4 BANJARMASIN
}

\author{
Vivi Aulia ${ }^{1}$, Hidya Maulida ${ }^{2}$, Kuzairi $^{3}$, Imam Hendra Saputra ${ }^{4}$ \\ ${ }^{1}$ STKIP PGRI Banjarmasin. Email: viviauliavasa@yahoo.com \\ ${ }^{2}$ STKIP PGRI Banjarmasin. Email: hidya.maulida@gmail.com \\ ${ }^{3}$ STKIP PGRI Banjarmasin. Email: spirit.ahmadkzr@gmail.com \\ ${ }^{4}$ STKIP PGRI Banjarmasin. Email: imam.hendra.s@english.stkipbjm.ac.id
}

\begin{abstract}
This article is a report of Community Service Program aiming at giving understanding and learning experience to the second grade students at SMKN 4 Banjarmasin in using English for tourism. The object of this program is 30 students of Tourism major. One day training program is carried out in form of practicing directly, doing demonstration, simulation, and role play in group. Furthermore, there are four topics to discuss as the material of this program, such as: using some expressions, information, and communication in English under tourism aspect. Generally, this program is well done. The students show their enthusiasm and demonstrate the activity successfully. There are still mistakes they have done in using grammar and pronouncing some English words. However, they show their best efforts running with the material given. Besides that, majority of them are unfamiliar with the specific terms used in English for tourism so that they need to be guided in understanding the meaning of it. At the end of this program, the students are expected to have learning experience and have mastery to communicate using foreign language in the future. It will become essential knowledge to challenge in the job market globally.
\end{abstract}

Keywords: Training, English, and tourism

\begin{abstract}
ABSTRAK
Artikel ini merupakan hasil dari kegiatan Pengabdian kepada Masyarakat yang bertujuan untuk memberikan pemahaman dan pengalaman belajar kepada siswa-siswi kelas XI Program Keahlian Usaha Perjalanan Wisata yang ada di SMKN 4 Banjarmasin dalam menggunakan Bahasa Inggris untuk pariwisata. Peserta kegiatan ini berjumlah 30 orang siswa. Kegiatan dilaksanakan dalam jangka waktu 1 hari dengan metode praktik secara langsung, demonstrasi, simulasi, dan bermain peran secara berkelompok. Sebanyak empat materi disajikan mengenai beberapa ungkapan, informasi, dan praktik komunikasi dalam Bahasa Inggris yang umum dan lazim digunakan dalam bidang pariwisata. Secara keseluruhan, kegiatan ini berjalan dengan baik. Siswa mampu mengikuti dan menampilkan demonstrasi secara langsung terkait materi yang diberikan. Walaupun masih terjadi banyak kesalahan dalam hal tata bahasa (grammar) dan pengucapan (pronunciation) Bahasa Inggris, siswa mampu menunjukkan usaha untuk memahami materi. Akan tetapi, mayoritas siswa masih belum familiar dengan kosakata-kosakata Bahasa Inggris tertentu dan spesifik berkaitan dengan kepariwisataan, sehingga perlu pendampingan untuk mengenal jenis kosakata-kosakata tersebut. Di akhir kegiatan, siswa diharapkan mendapatkan pengalaman belajar yang akan menjadi salah satu modal bagi mereka untuk ikut bersaing di dunia kerja yang secara global menuntut kecakapan berkomunikasi dalam bahasa asing.
\end{abstract}

Kata Kunci: Pelatihan, Bahasa Inggris, pariwisata 
Aulia, Pelatihan Penggunaan Bahasa Inggris....41

\section{PENDAHULUAN}

Pariwisata (tourism) merupakan salah satu aspek sosial dalam kehidupan masyarakat yang turut memberikan kontribusi dalam pengembangan sumber daya alam dan sumber daya manusia di Indonesia. Sebagai negara yang memiliki ribuan pulau, sektor pariwisata Indonesia telah berkembang dengan sangat pesat. Pariwisata yang berbasis alam dan buatan yang ada di Indonesia kian gencar diminati oleh pengunjung (turis) baik dari dalam negeri maupun dari luar negeri. Hal ini tidak terlepas dari komitmen Pemerintah Indonesia yang selalu mendukung dan mendorong tumbuh dan kembangnya pariwisata lokal setempat yang pada akhirnya akan menjadi ikon pariwisata nasional dengan dukungan sumber daya manusia yang maksimal.

Sektor pariwisata kian berkembang di sejumlah daerah di Indonesia. Apabila di tahun-tahun sebelumnya hanya kota besar saja yang terkenal dengan daerah yang memiliki banyak tempat pariwisata, maka seiring dengan laju pertumbuhan ekonomi di setiap wilayah, kota-kota kecil pun telah memiliki daerah pariwisata lokal. Beberapa pariwisata lokal tersebut bahkan mampu memberikan kontribusi terhadap pengembangan sumber daya manusia di sekitarnya (Bonita, 2016:1500). Promosi terhadap sektor pariwisata lokal semakin gencar dilakukan melalui media massa, televisi, media sosial, dan sejenisnya. Bahkan, saat ini promosi melalui ajang kompetisi duta pariwisata juga telah banyak dilakukan di sejumlah daerah untuk mengenalkan potensi dan keberagaman sektor pariwisata yang tersedia.

Salah satu provinsi di Indonesia yang sektor pariwisatanya sedang berkembang adalah Provinsi Kalimantan Selatan. Provinsi dengan Banjarmasin sebagai ibukotanya ini merupakan salah satu daerah yang terkenal dengan lahan basah (wetland) yang karakteristiknya adalah berada di bawah permukaan laut, mayoritas tanahnya berupa rawa-rawa, serta kondisi lingkungan sangat bergantung pada pasang surut air laut. Dengan kondisi demikian, maka mayoritas daerah yang ada di provinsi Kalimantan Selatan dikelilingi oleh banyak sungai-sungai yang bermuara ke laut (Notohadiprawiro, 1997:1-7).

Implikasi dari kondisi geografis provinsi Kalimantan Selatan yang berbeda dengan daerah lain di Indonesia, maka sektor pariwisata alam menjadi sangat dominan. Geliat promosi pariwisata gencar dilakukan oleh Pemerintah Provinsi Kalimantan Selatan. Sektor-sektor pendukung lainnya, seperti: sumber daya manusia, sarana dan prasarana, akses transportasi, dan akses komunikasi diberdayakan secara bertahap. Tujuannya adalah agar pembangunan sektor pariwisata memberikan kontribusi dan dampak positif terhadap lingkungan dan masyarakat setempat. Beberapa lokasi pariwisata berbasis alam yang ada di provinsi Kalimantan Selatan semakin diminati oleh pengunjung, seperti: Wisata Susur Sungai, Pasar Terapung, Pantai Pagatan, Pantai Asmara, Pulau Kembang, Pantai Batakan, dan masih banyak lagi obyek pariwisata lainnya.

Di antara sektor-sektor pendukung pembangunan pariwisata, sumber daya manusia (human resources) merupakan sektor utama yang sangat penting untuk diperhatikan. Orang-orang yang terlibat (human) atau memiliki profesi di bidang pariwisata mutlak harus menguasai seluk beluk bidang yang digelutinya. Di bidang 
pariwisata misalnya, diperlukan pramuwisata (tourist guide) dan agen perjalanan wisata (travel agent) yang bertugas menjadi pemandu bagi pengunjung sebuah tempat wisata. Mereka yang bekerja di bidang tersebut tentu harus memiliki kemampuan yang profesional agar dapat menjalankan tugasnya dengan baik dan maksimal.

Sebagai upaya mempersiapkan orang-orang yang profesional terlibat dalam bidang pariwisata, maka Pemerintah memasukkan pendidikan kepariwisataan sebagai salah satu program keahlian pada jenjang Sekolah Menengah Kejuruan (SMK). Beberapa jenjang vokasi ini menawarkan Pariwisata (tourism) dan hal-hal berkaitan kepariwisataan lainnya yang bisa dipilih bagi lulusan SMP yang ingin menempuh pendidikan selanjutnya di jenjang SMK. Harapannya adalah siswa-siswa lulusan SMK yang memilih Program Keahlian tersebut dapat mengaplikasikan ilmunya secara praksis di lapangan.

Selain itu, upaya lain untuk mempersiapkan orang-orang profesional di bidang pariwisata adalah melatih kemampuan Bahasa Inggris sebagai bahasa asing yang digunakan untuk berkomunikasi. Tidak dapat dipungkiri bahwa salah satu faktor yang menjadi kendala di sektor pariwisata adalah minimnya penguasaan Bahasa Inggris. Pengunjung yang datang ke suatu tempat wisata tidak hanya berasal dari dalam negeri saja. Pengunjung yang berasal dari luar negeri pun juga sangat banyak. Bahasa Inggris sebagai bahasa internasional menjadi alat komunikasi yang seharusnya bisa menjembatani komunikasi yang interaktif antara masyarakat lokal dan pengunjung yang berasal dari luar negeri.

Berdasarkan paparan di atas, menjadi sangat penting agar siswa siswi di jenjang SMK yang mengambil Program Keahlian Pariwisata diberikan pelatihan mengenai penggunaan Bahasa Inggris yang aplikatif. Tentunya, pelatihan yang akan diberikan juga mengintegrasikan pariwisata lokal yang ada di Kalimantan Selatan sebagai contoh nyata yang lekat dengan lingkungan siswa. Atas dasar hal tersebut, maka Tim Pengabdian kepada Masyarakat melaksanakan program Pelatihan Penggunaan Bahasa Inggris Untuk Pariwisata (English for Tourism) pada Siswa SMKN 4 Banjarmasin. Tujuan dari kegiatan ini adalah memberikan pelatihan dan pemahaman agar siswa memiliki kemampuan dasar Bahasa Inggris yang dapat digunakan untuk berkomunikasi dalam bidang kepariwisataan. Tujuan lainnya adalah memberikan pengalaman belajar (learning experience) kepada siswa dalam menerapkan dan menggunakan Bahasa Inggris yang berkaitan dengan kepariwisataan dalam dunia kerja.

\section{METODE PELAKSANAAN}

Kegiatan Pengabdian kepada Masyarakat yang dilakukan di SMKN 4 Banjarmasin ini memilih sasaran siswa siswi kelas XI yang mengambil Program Keahlian Usaha Perjalanan Wisata (UPW) pada tahun pelajaran 2016/2017. Jumlah siswa-siswi sebagai peserta kegiatan ini berjumlah 30 orang. Metode pelaksanaan kegiatan Pengabdian kepada Masyarakat ini adalah pelatihan langsung kepada siswa-siswi kelas kelas XI SMKN 4 Banjarmasin dalam bentuk praktik langsung baik secara lisan maupun tertulis.

Pelatihan penggunaan Bahasa Inggris ini berlangsung selama 1 hari penuh dan dilakukan dalam 3 tahap. Pertama, pengenalan (introduction) yang kemudian 
dilanjutkan dengan paparan teori (theoretical review). Kedua, penjelasan dan pemberian contoh/model komunikasi Bahasa Inggris tentang kepariwisataan yang diikuti dengan kegiatan tanya jawab secara interaktif. Terakhir, siswa-siswi melaksanakan praktik secara berkelompok, role play, demonstrasi, dan simulasi sesuai arahan dari tim pengabdian.

Materi yang diberikan dalam kegiatan Pelatihan Bahasa Inggris untuk Pariwisata ini dipresentasikan dalam Table 1. Siswa diberikan materi dalam bentuk handout serta soft copy rekaman gambar dan video. Media yang digunakan untuk membantu kelancaran proses kegiatan ini adalah LCD proyektor, laptop, papan tulis, microphone, dan audio. Detail materi kegiatan ini dipaparkan pada Tabel 1 berikut:

Tabel 1 Paparan Materi Kegiatan Pengabdian kepada Masyarakat

\begin{tabular}{|c|c|c|c|}
\hline Materi & Topik & Alokasi Waktu & Kegiatan \\
\hline I & $\begin{array}{l}\text { Expressing for greeting and } \\
\text { welcoming tourists } \\
\text { a. Using the right expressions } \\
\text { for greeting and welcoming } \\
\text { tourist } \\
\text { b. Demonstrating how to greet } \\
\text { and welcome tourists } \\
\text { appropriately } \\
\text { c. Introducing ourself to } \\
\text { tourists adequately }\end{array}$ & 2 jam & $\begin{array}{l}\text { Praktik, simulasi, dan role } \\
\text { play }\end{array}$ \\
\hline II & $\begin{array}{l}\text { Asking and giving tourists } \\
\text { information } \\
\text { a. Using appropriate } \\
\text { expressions to ask and give } \\
\text { information to tourists } \\
\text { b. Demonstrating how to ask } \\
\text { and give information to } \\
\text { tourists } \\
\text { c. Demonstrating how to give } \\
\text { sufficient information needed } \\
\text { by tourists }\end{array}$ & 2 jam & $\begin{array}{l}\text { Praktik, simulasi, role play, } \\
\text { demonstrasi, diskusi } \\
\text { kelompok, presentasi }\end{array}$ \\
\hline III & $\begin{array}{l}\text { Preparing tour itineraries } \\
\text { a. Identifying the content of } \\
\text { tour itinerary } \\
\text { b. Showing an example of tour } \\
\text { itinerary } \\
\text { c. Creating an itinerary for } \\
\text { Banjarmasin Fascinating } \\
\text { Tour Itinerary }\end{array}$ & $2.5 \mathrm{jam}$ & $\begin{array}{l}\text { Diskusi kelompok, praktik, } \\
\text { dan presentasi }\end{array}$ \\
\hline IV & $\begin{array}{l}\text { Explaining tourism object } \\
\text { a. Identifying places of } \\
\text { interest in Kalimantan } \\
\text { Selatan } \\
\text { b. Informing tourists places of } \\
\text { interest in Kalimantan } \\
\text { Selatan } \\
\text { c. Suggesting tourists where } \\
\text { to go in Kalimantan Selatan }\end{array}$ & $1.5 \mathrm{jam}$ & Presentasi, simulasi \\
\hline
\end{tabular}




\section{HASIL DAN PEMBAHASAN}

Hasil dan pembahasan kegiatan pelatihan penggunaan Bahasa Inggris yang dilaksanakan pada siswa-siswi Kelas XI Program Keahlian Usaha Perjalanan Wisata (UPW) di SMKN 4 Banjarmasin dipaparkan sebagai berikut:

\section{Hasil}

Hasil kegiatan diuraikan berdasarkan pada setiap rincian materi dan kegiatan yang dilakukan. Pertama, pada materi awal yang membahas mengenai ungkapan untuk pertemuan dan perpisahan (expressions for greeting and welcoming tourists) berjalan dengan baik dan interaktif. Pada dasarnya, siswa-siswi kelas XI dari Program Keahlian Usaha Perjalanan Wisata (UPW) yang ada di SMKN 4 Banjarmasin telah mengenal bentuk ekspresi ini. Ekspressions for greeting and welcoming merupakan salah satu materi yang ada pada pelajaran Bahasa Inggris di jenjang SMP, sehingga rata-rata siswa sudah mengenal dan mempunyai background knowledge mengenai ungkapan tersebut. Mayoritas siswa mampu praktik secara langsung di depan kelas, role play, dan mensimulasikan variasi-variasi ungkapan ini secara sederhana berdasarkan dari apa yang sudah mereka ketahui dan pahami. Contoh dari hasil yang ditampilkan siswa adalah sebagai berikut:

A tourist arrives at the Syamsudin Noor airport

Student A : Good morning, Sir. Are you Mr. Nixon from London?

Student B : Good morning. Yes, I am Nixon.

Student A : Welcome to Banjarmasin. How was the flight, Sir?

Student B : The flight is very nice. I wish I can enjoy every time visiting many places here

Student A : Yes, of course. This is our car. Please, get in the car, Mr. Nixon

StudentB: Ok. Thank you.

Kedua, hasil yang didapat dari paparan materi mengenai ungkapan bertanya dan memberikan informasi kepada turis (asking and giving tourist information). Pada materi ini, siswa diajak untuk mendemonstrasikan bagaimana memberikan informasi mengenai tempat-tempat pariwisata, lokasi, jarak yang ditempuh, harga tiket masuk, dan hal-hal lainnya yang berkaitan dengan informasi kepada pengunjung. Tidak seperti pada materi pertama dimana rata-rata siswa mampu praktik secara langsung menampilkan ungkapan pertemuan dan perpisahan, pada materi kedua ini siswa cenderung mengalami kesulitan. Kesulitan yang dialami siswa dikarenakan masih belum familiarnya mereka dengan pola komunikasi untuk bertanya dan memberikan informasi kepada turis.

Disamping itu, kesulitan yang dihadapi siswa untuk memahami materi kedua ini adalah masih banyaknya kosakata (vocabulary) Bahasa Inggris terkait kepariwisataan yang belum akrab di telinga siswa. Sebagai contoh: beberapa siswa belum bisa membedakan penggunaan istilah tour, trip, vacation, dan holiday ketika memberikan informasi kepada turis. Contoh yang lainnya, siswa kurang familiar dengan istilah money changer, luggage, itinerary, dan sejenisnya. Untuk mengatasi kesulitan siswa dalam hal pemahaman kosakata yang tidak dipahami seperti ini, tim pengabdian kepada 
masyarakat membantu memberikan pemahaman akan arti dan makna kosakatakosakata tersebut serta meminta mereka untuk membuka kamus.

Berikutnya, penyampaian materi ketiga yang membahas mengenai pembuatan rencana atau acara perjalanan (preparing tour itinerary) berjalan dengan baik. Pada bagian ini, siswa diajak mengidentifikasi rencana atau acara perjalanan yang dibuat untuk diinformasikan kepada turis. Secara berkelompok, siswa diminta menyusun schedule perjalanan bagi para turis yang berkunjung ke Kalimantan Selatan. Contoh dari hasil yang dibuat oleh siswa ditampikan pada Tabel 2 berikut:

Tabel 2 Hasil Kerja Salah Satu Kelompok Siswa Membuat

Tour Itinerary

\begin{tabular}{ll}
\hline \multicolumn{1}{c}{ Time } & \multicolumn{1}{c}{ Activity } \\
\hline 05.00 & Visiting Pasar Terapung at Sungai Kuin, Banjarmasin \\
\hline 07.00 & Having breakfast at Swissbell Hotel \\
\hline 08.00 & Leaving the hotel for Siring Martapura \\
\hline 08.45 & Arriving at Siring Martapura and enjoying the scenery \\
\hline 10.00 & Leaving the Siring Martapura for visiting Museum Wasaka \\
\hline 10.20 & Arriving at Museum Wasaka \\
\hline 12.00 & Leaving the Museum Wasaka for lunch \\
\hline 12.30 & Lunch at Soto Bang Amat, Banjarmasin \\
\hline 13.30 & Leaving for the next destination. Going to Duta Mall \\
\hline 16.00 & Arriving at Duta Mall for shopping \\
\hline
\end{tabular}

Terakhir, penyampaian materi ke empat yang membahas mengenai obyekobyek pariwisata (explaining tourism object) yang ada di provinsi Kalimantan Selatan. Pada bagian ini, siswa diajak untuk berlatih berbicara (speaking) yang mana kegiatan ini akan sangat bermanfaat untuk diterapkan secara langsung dan aktif kepada turis yang berkunjung. Bentuk praktik yang dilakukan siswa yaitu secara berkelompok menjelaskan salah satu obyek pariwisata yang juga mengandung kosakata-kosata tertentu dalam Bahasa Inggris, seperti kosakata mengenai direction (arah), public places (tempat-tempat umum), rambu-rambu lalu lintas, dan sejenisnya.

Penyampaian materi ke empat berjalan dengan baik. Secara berkelompok, siswa bekerja sama membuat draf tertulis mengenai obyek wisata untuk kemudian dipraktikkan secara lisan. Beberapa kelompok mengalami kesulitan dalam mengerjakan dikarenakan belum familiarnya mereka dengan kosakata-kosakata Bahasa Inggris tertentu serta minimnya pengetahuan mereka akan informasi mengenai obyek wisata yang ada di Kalimantan Selatan. Contoh dari hasil yang dikerjakan salah satu kelompok siswa adalah sebagai berikut:

Pulau Kembang is one of famous tourism object at South Kalimantan. The location is not far from Banjarmasin as capital city of it. Administratively, this place included in Barito Kuala. We can walk around Pulau Kembang to see a group of monkeys. Usually, tourists prepare themselves with peanuts or bananas to be given to the monkey. People around this place believe that groups of monkey here are descendants of followers of the Monkey God. This is very beautiful place to visit. 
Dari hasil tersebut, ditemukan bahwa siswa masih melakukan kesalahan dalam penggunaan tata bahasa (grammar) dan pengucapan (pronunciation) Bahasa Inggris. Terlepas dari hal tersebut, para siswa mampu menunjukkan usaha, keberanian, dan antusiasme untuk mau berbicara (speaking) mempraktikkan materi yang diberikan. Walaupun beberapa kali melakukan kesalahan dalam tata bahasa dan pengucapan Bahasa Inggris, para siswa mampu percaya diri menampilkan hasil kerja mereka.

\section{Pembahasan}

Pada pelaksanaan kegiatan pengabdian kepada masyarakat ini, antusiasme siswa dan siswi yang berasal dari kelas XI Program Keahlian Usaha Perjalanan Wisata (UPW) di SMKN 4 Banjarmasin saat mengikuti pelatihan penggunaan Bahasa Inggris untuk Pariwisata (English for Tourism) ini patut diberikan apresiasi. Pasalnya, peserta kegiatan ini yang berjumlah 30 orang memiliki keinginan sangat serius untuk belajar bagaimana menggunakan Bahasa Inggris untuk berkomunikasi dengan turis dengan setting pariwisata yang ada di Kalimantan Selatan. Antusiasme dalam belajar dan mengikuti pelatihan ini menunjukkan bahwa mereka menyadari untuk menjadi pelaku usaha di bidang pariwisata saja tidaklah cukup bermodalkan penampilan dan finansial. Kemampuan (skill) lainnya yang tidak kalah penting untuk mendukung pasar kerja di aspek pariwisata adalah penguasaan bahasa asing.

Hasil yang pertama berkaitan dengan kegiatan siswa mempraktikkan expression greeting and welcoming to tourists seperti yang dipaparkan pada bagian sebelumnya berjalan dengan lancar. Siswa kelas XI yang mengambil Program Keahlian Usaha Perjalanan Wisata (UPW) sudah mengenal dan mempelajari ungkapan ini karena sudah diajarkan ketika mereka duduk di kelas VII jenjang SMP. Hal ini tercantum pada Silabus Mata Pelajaran Bahasa Inggris SMP/MTs Kelas VII Kurikulum 2013 pada pernyataan Kompetensi Dasar poin 3.1 yang berbunyi Mengidentifikasi fungsi sosial, struktur teks, dan unsur kebahasaan teks interaksi interpersonal lisan dan tulis yang melibatkan tindakan menyapa, berpamitan, mengucapkan terimakasih, dan meminta maaf, serta menanggapinya, sesuai dengan konteks penggunaannya (Kementerian Pendidikan dan Kebudayaan,2016:12).

Berikutnya, hasil dari pertemuan kedua yang membahas mengenai ungkapan bertanya dan memberikan informasi kepada turis (asking and giving tourist information). Seperti yang sudah dijelaskan pada bagian sebelumnya bahwa penyampaian materi ini juga berjalan dengan baik. Akan tetapi, mayoritas siswa mengalami kesulitan dalam menggunakan kosakata-kosakata (vocabulary) baru yang spesifik dan khusus berkaitan dengan kepariwisataan. Hal ini bisa dimaklumi karena berdasarkan informasi yang diberikan oleh Guru Pengajar Mata Pelajaran Bahasa Inggris di SMKN 4 Banjarmasin, bahwa rata-rata siswa hanya menguasai kosakata Bahasa Inggris yang umum saja. Banyak diantara mereka yang baru mengenal kosakata khusus mengenai kepariwisataan ketika mengikuti kegiatan ini.

Sebagai bahasa asing resmi di Indonesia, Bahasa Inggris telah masuk ke kurikulum pendidikan sejak di jenjang sekolah dasar hingga ke tingkat menengah. Di jenjang menengah (SMP, SMA, dan SMK sederajat), Bahasa Inggris telah menjadi mata 
pelajaran wajib bagi siswa. Hal ini sebagaimana tercantum dalam Lampiran Peraturan Menteri Pendidikan dan Kebudayaan Nomor 70 Tahun 2013 pada halaman 14, pada Kurikulum 2013 yang diberlakukan saat ini di Indonesia, mata pelajaran Bahasa Inggris di jenjang Sekolah Menengah Kejuruan (SMK) dikategorikan dalam Kelompok Mata Pelajaran Wajib (A) dengan alokasi waktu 2 jam perminggu.

Implikasi dari Kurikulum 2013 yang mengalokasikan mata pelajaran Bahasa Inggris hanya 2 jam perminggu membuat pembelajaran Bahasa Inggris di SMK sangat terbatas. Disamping alokasi waktu yang sangat sedikit, materi Bahasa Inggris yang tercantum di silabus Kurikulum 2013 juga masih mencakup materi Bahasa Inggris secara umum (general English). Kisaran materi masih berkaitan tentang jenis-jenis teks (genre) yang diberikan sesuai dengan jenjang kelas X, XI, dan XII yang pembagiannya masing-masing tercantum pada silabus tersebut. Pembelajaran Bahasa Inggris yang berkaitan dengan program keahlian siswa belum diajarkan secara khusus. Oleh karena itu, tim pengabdian kepada masyarakat memberikan motivasi kepada siswa agar terus belajar menambah pengetahuan dan memperkaya kosakata-kosakata Bahasa Inggris dengan memperbanyak bacaan dan referensi.

Hasil berikutnya berkaitan dengan materi menyusun rencana atau acara perjalanan (preparing tour itineraries). Siswa menunjukkan antusiasme ketika diminta menampilkan tour itinerary yang mereka buat secara berkelompok. Membuat rencana atau acara perjalanan dalam Bahasa Inggris sangat penting untuk dipelajari. Tidak hanya turis lokal yang mengunjungi obyek pariwisata, tetapi juga turis mancanegara memerlukan informasi rinci dari setiap obyek wisata yang dikunjunginya. Hal ini dikarenakan tour itinerary memuat informasi rinci mengenai time and place (waktu dan tempat yang akan dikunjungi), hotel tempat menginap, transportasi yang digunakan, makanan yang disediakan, serta terms and condition (syarat dan kondisi) perjalanan yang akan dilakukan (Pribadi, 2006:33). Oleh karena itu, siswa diberikan pengetahuan mengenai penyusunan tour itinerary ini.

Terakhir, hasil materi ke empat yang membahas mengenai obyek pariwisata menuntut siswa untuk mengenal lebih dekat kekayaan alam yang ada di Kalimantan Selatan. Tidak hanya mengetahui obyek pariwisata yang ada di Banjarmasin sebagai ibukota, akan tetapi siswa diajak untuk menggali informasi dari sekian banyak tempat yang menarik tersebar di Kalimantan Selatan. Hal ini sejalan dan melekat dengan salah satu muatan pendidikan karakter yg ada pada Kurikulum 2013 yaitu cinta tanah air. Salah satu indikator nilai karakter cinta tanah air yang bisa dilakukan oleh siswa adalah menyediakan informasi, baik dari sumber cetak maupun elektronik mengenai kekayaan alam dan budaya di Indonesia (Nurohmah, 2016:41). Dengan demikian, siswa tidak hanya semata-mata melatih diri untuk menggunakan Bahasa Inggris dalam bidang kepariwisataan. Akan tetapi, ada usaha untuk menanamkan nilai-nilai karakter yang positif didapat dengan mengikuti kegiatan ini.

Pengalaman belajar yang bisa didapat dari kegiatan ini adalah bahwa berkecimpung di dunia pariwisata membutuhkan ketekunan dan kemauan untuk mempelajari semua hal. Tidak hanya mempelajari seluk beluk mengenai pariwisata (tourism), tempat-tempat wisata (tourism places), agen perjalanan wisata (travel agent), 
dan hal-hal lainnya berkaitan dengan pariwisata yang lain. Memiliki keahlian khusus di bidang bahasa juga sangat mutlak diperlukan. Kefasihan berbahasa seringkali menjadi kendala di kalangan para siswa. Masih banyaknya lapisan masyarakat yang menggunakan bahasa ibu untuk berkomunikasi secara formal membuat kefasihan berbahasa Indonesia juga menjadi kendala. Ini terbukti ketika kegiatan pengabdian kepada masyarakat dilaksanakan di SMKN 4 Banjarmasin. Beberapa siswa terlihat masih menggunakan bahasa ibu untuk berkomunikasi secara formal dengan guru di lingkungan sekolah. Beberapa siswa yang lain terdengar menggunakan Bahasa Indonesia. Pada mata pelajaran Bahasa Inggris pun belum sepenuhnya siswa mau menggunakan Bahasa Inggris tersebut untuk berkomunikasi. Berdasarkan contoh kecil tersebut, kemampuan berbahasa, baik menggunakan bahasa Indonesia maupun bahasa asing, menjadi sesuatu yang penting untuk dipelajari siswa sebagai sarana untuk mendukung komunikasi di dunia kerja nantinya.

Disamping lancarnya kegiatan ini, masih terdapat beberapa hal yang perlu dievaluasi. Alokasi waktu yang terbatas hanya 1 hari dirasa kurang untuk memberikan kesempatan kepada siswa mempraktikkan penggunaan Bahasa Inggris untuk kepariwisataan lebih intensif. Setidaknya, setelah selesai kegiatan ini, para siswa mendapatkan pengalaman belajar mengenai penggunaan Bahasa Inggris yang harapannya bermanfaat bagi mereka menghadapi dunia kerja setelah lulus dari jenjang SMK.

\section{SIMPULAN}

Kegiatan pengabdian kepada masyarakat yang bertemakan Pelatihan Penggunaan Bahasa Inggris untuk pariwisata (English for Tourism) yang telah dilaksanakan di SMKN 4 Banjarmasin menjadi salah satu implementasi kegiatan Tri Dharma Perguruan Tinggi. Mata pelajaran Bahasa Inggris yang alokasi waktunya masih terbatas diajarkan di jenjang SMK, memungkinkan untuk memberikan pelatihan Bahasa Inggris yang lebih khusus kepada siswa sesuai dengan Program Keahlian mereka. Antusiasme siswa sebagai peserta pelatihan menunjukkan bahwa mereka sedang mempelajari sesuatu yang baru, yang secara khusus belum diajarkan di sekolah. Pengalaman belajar (learning experience) telah didapat oleh siswa walaupun masih belum seluruhnya dapat dipraktikkan dengan intensif. Tentunya, pengalaman belajar ini akan menjadi salah satu modal bagi mereka untuk ikut bersaing di dunia kerja yang secara global menuntut kecakapan berkomunikasi dalam bahasa asing.

\section{DAFTAR RUJUKAN}

Bonita, N. (2016). Peran Dinas kebudayaan dan Pariwisata dalam Meningkatkan Kunjungan Wisatawan Labuan Cermin di Kabupaten Berau. E-Journal Ilmu Pemerintahan, 4 (4): 1499-1510. Dari ejournal.ip.fisip.unmul.ac.id

Lampiran Peraturan Menteri Pendidikan dan Kebudayaan Republik Indonesia Nomor 7 Tahun 2013 tentang Kerangka Dasar dan Struktur Kurikulum Sekolah Menengah Kejuruan/Madrasah Aliyah Kejuruan 
Leo, S. 2016. English for Professional Tour Guiding Services. Jakarta: PT Gramedia Pustaka Utama

Nurohmah, E.Z. (2016). Implementasi Pendidikan Karakter di SDN Plebengan, Bambanglipuro, Bantul. Skripsi Tidak Diterbitkan. Yogyakarta: Universitas Negeri Yogyakarta

Notohadiprawiro, T. (1997). Lahan Basah (Terra Incognita). Prosiding Seminar Nasional Pemberdayaan Lahan Basah Pantai Timur Sumatera yang Berwawasan Lingkungan Menyongsong Abad ke 21. Hal 1-10. Jambi: Fakultas Pertanian Universitas Jambi

Pribadi, N.N. I.R. (2006). Peranan Nawang Tours dalam Meningkatkan Industri Pariwisata. Tugas Akhir Tidak Diterbitkan. Bandung: Universitas Widyatama

Silabus Mata Pelajaran Sekolah Menengah Pertama/Madrasah Tsanawiyah (SMP/MTs). (2016. Jakarta: Kementerian Pendidikan dan Kebudayaan. 